\title{
Cutaneous Allodynia in Migraine: A Narrative Review
}

\begin{abstract}
Ane Mínguez-Olaondo ${ }^{1,2,3,4,5}$, Sonia Quintas ${ }^{6}$, Noemí Morollón Sánchez-Mateos ${ }^{7}$, Alba López-Bravo ${ }^{8,9}$, Marta Vila-Pueyo ${ }^{10}$, Vesselina Grozeva ${ }^{11}$, Robert Belvís ${ }^{7}$, Sonia Santos-Lasaosa ${ }^{9,12}$ and Pablo Irimia ${ }^{5 *}$

${ }^{1}$ Neurology Department, Hospital Universitario Donostia, San Sebastián, Spain, ${ }^{2}$ Athenea Neuroclinics, Policlínica Guipúzcoa, Grupo Quirón Salud Donostia, San Sebastián, Spain, ${ }^{3}$ Neuroscience Area, Biodonostia Health Institute, Donostia, Spain, ${ }^{4}$ Medicine Faculty, University of Deusto, Billbao, Spain, ${ }^{5}$ Clínica Universidad de Navarra, Pamplona, Spain, ${ }^{6}$ Hospital Universitario de la Princesa, Madrid, Spain, ${ }^{7}$ Headache and Neuralgia Unit, Neurology Department, Hospital de la Santa Creu i Sant Pau, Barcelona, Spain, ${ }^{8}$ Hospital Reina Sofía, Tudela, Spain, ${ }^{9}$ Instituto de Investigación Sanitaria Aragón, Zaragoza, Spain, ${ }^{10}$ Headache and Neurological Pain Research Group, Department of Medicine, Vall d'Hebron Research Institute, Universitat Autònoma de Barcelona, Barcelona, Spain, ${ }^{11}$ Private Neurology Practice, Sofia, Bulgaria, ${ }^{12}$ Hospital Clínico Universitario Lozano Blesa, Zaragoza, Spain
\end{abstract}

\section{OPEN ACCESS}

Edited by:

Simona Sacco,

University of L'Aquila, Italy

Reviewed by:

Gianluca Coppola,

Sapienza University of Rome, Italy

Giuseppe Cosentino,

University of Pavia, Italy

*Correspondence:

Pablo Irimia

pirimia@unav.es

Specialty section: This article was submitted to Headache and Neurogenic Pain,

a section of the journal

Frontiers in Neurology

Received: 07 December 2021 Accepted: 29 December 2021

Published: 21 January 2022

Citation:

Mínguez-Olaondo A, Quintas S,

Morollón Sánchez-Mateos N,

López-Bravo A, Vila-Pueyo M, Grozeva V, Belvis R,

Santos-Lasaosa $S$ and Irimia $P$ (2022)

Cutaneous Allodynia in Migraine: A Narrative Review.

Front. Neurol. 12:831035. doi: 10.3389/fneur.2021.831035
Objective: In the present work, we conduct a narrative review of the most relevant literature on cutaneous allodynia $(C A)$ in migraine.

Background: CA is regarded as the perception of pain in response to non-noxious skin stimulation. The number of research studies relating to CA and migraine has increased strikingly over the last few decades. Therefore, the clinician treating migraine patients must recognize this common symptom and have up-to-date knowledge of its importance from the pathophysiological, diagnostic, prognostic and therapeutic point of view.

Methods: We performed a comprehensive narrative review to analyze existing literature regarding CA in migraine, with a special focus on epidemiology, pathophysiology, assessment methods, risk for chronification, diagnosis and management. PubMed and the Cochrane databases were used for the literature search.

Results: The prevalence of CA in patients with migraine is approximately $60 \%$. The mechanisms underlying CA in migraine are not completely clarified but include a sensitization phenomenon at different levels of the trigemino-talamo-cortical nociceptive pathway and dysfunction of brainstem and cortical areas that modulate thalamocortical inputs. The gold standard for the assessment of CA is quantitative sensory testing (QST), but the validated Allodynia 12-item questionnaire is preferred in clinical setting. The presence of CA is associated with an increased risk of migraine chronification and has therapeutic implications.

Conclusions: CA is a marker of central sensitization in patients with migraine that has been associated with an increased risk of chronification and may influence therapeutic decisions.

Keywords: cutaneous allodynia, migraine, migraine chronification, risk factors, treatment 


\section{INTRODUCTION}

Cutaneous allodynia (CA) is defined as pain resulting from application of a non-noxious stimulus to normal skin $(1,2)$, and is classified according to either the sensory modality that is used to elicit the sensation (thermal, mechanical dynamic, and mechanical static allodynia) or by the location of the symptom (cephalic and extracephalic). The presence of $\mathrm{CA}$ in patients with migraine was described more than 100 years ago (3), but only recently a growing number of studies began to highlight the importance of this common and bothersome symptom $(2,4-6)$. Therefore, the clinician treating migraine patients must recognize CA (7) and have up-to-date knowledge of CA importance from pathophysiological, diagnostic, prognostic and therapeutic point of view.

In the present work, we performed a comprehensive narrative review to analyze the most relevant literature on CA in migraine, with a special focus on epidemiology, pathophysiology, assessment methods, risk for chronification, diagnosis, and management.

\section{METHODS}

We conducted a non-systematic literature search in PubMed and Cochrane databases for published manuscripts on allodynia and migraine in October 2021, with no date limits. Search terms were limited to migraine and allodynia. The articles were selected independently by the authors based on the intrinsic characteristics and value of the studies. Articles addressing epidemiology, pathophysiology, evaluation tools, risk for chronification, diagnosis and management in patients with CA were included. The search included publications in English and Spanish.

\section{EPIDEMIOLOGY OF ALLODYNIA IN MIGRAINE}

The prevalence of CA in migraine is highly variable $(8,43)$ in the literature (Table 1), although it can be considered that between 40 and $70 \%$ of the patients with migraine experience this symptom, according to population-based studies $(26,36$, 37). Several factors influence these differences including the heterogeneity of the populations in each study (populationbased nationwide studies, cross-sectional studies or prospective case series) and the methodology used for the identification of CA (8-43).

Two of the largest population-based studies were conducted in the United States to assess the prevalence of CA in patients with migraine $(36,37)$. Prevalence rates range from 39 to $63 \%$ $(36,37)$. In both studies, migraine diagnosis was made using validated questionnaires, not through a medical consultation, and 12-item Allodynia Symptom Checklist (ASC-12) was used to detect CA. The population studies published to date have large sample sizes that allow the analysis of patients by subgroups and facilitate the study of the influence of different clinical and sociodemographic variables on the appearance of CA. In this sense, a higher prevalence of CA has been observed in women, in patients with frequent migraine and in those with anxiety and/or depression, and acute medication overuse (36, 37, 44). Some studies also found that CA increased with body mass index (BMI) $(34,45,46)$. Furthermore, Louter et al. (26) developed a study with a similar design in the Netherlands and found a $70 \%$ prevalence of CA in patients with migraine. The risk factors identified for developing CA, included lifetime depression, female gender, low age at onset, and high migraine attack frequency, but not BMI. Other investigators have studied the prevalence of migraine in cohorts of patients recruited from a single-center and with a limited number of subjects (Table 1), which makes it difficult to generalize the results and explain, at least in part, the wide range found in the prevalence of CA.

One of the findings that is consistently observed in most studies is that CA increased with headache frequency suggesting that repeated migraine attacks lead to the development of allodynia. Some studies also describe that the presence of AC is more frequent in patients with migraine with aura (37) and in those who overuse analgesics (44).

In the coming years, the widespread use of the ASC-12 scale will allow us to have more data on the prevalence of CA. It would be very useful to have data obtained in large series of patients, attended in different centers, in which the diagnosis of migraine has been made by a specialist in a face-to-face interview.

\section{PATHOPHYSIOLOGY OF ALLODYNIA IN MIGRAINE}

The mechanisms underlying $\mathrm{CA}$ in migraine are still not completely understood but include a sensitization phenomenon at different levels of the trigemino-vascular system and ascending projections, and a dysfunction of the different brainstem and cortical areas that modulate thalamocortical inputs $(47,48)$ (Figure 1). The trigeminal ganglion (TG) gives rise to pseudo-unipolar trigeminal primary afferents that project to peripheral and central sites. In the periphery, the nociceptive fibers from TG neurons innervate the meninges, dural blood vessels, middle meningeal artery, and large cerebral arteries. Activation and sensitization of these peripheral structures occurs by the local release of vasoactive peptides, such as calcitonin gene-related peptide (CGRP), amylin, substance $\mathrm{P}$ and pituitary adenylate cyclase-activating peptide (PACAP) (49-52), and inflammatory mediators (49). Sensitization of peripheral afferent TG fibers, or peripheral sensitization, explains the characteristic throbbing pain that worsens with physical activity during migraine attacks (49). Peripheral sensitization also implies that the threshold needed by these first-order neurons of the TG to respond to a stimulus decreases and that the magnitude of the response is increased (47).

There are central afferent projections from the TG neurons to the trigeminal nucleus caudalis (TNC) and the upper cervical spinal cord (C1-C2) (53). The TNC receives repetitive, 
TABLE 1 | Most relevant studies regarding different epidemiological aspects of CA in migraine.

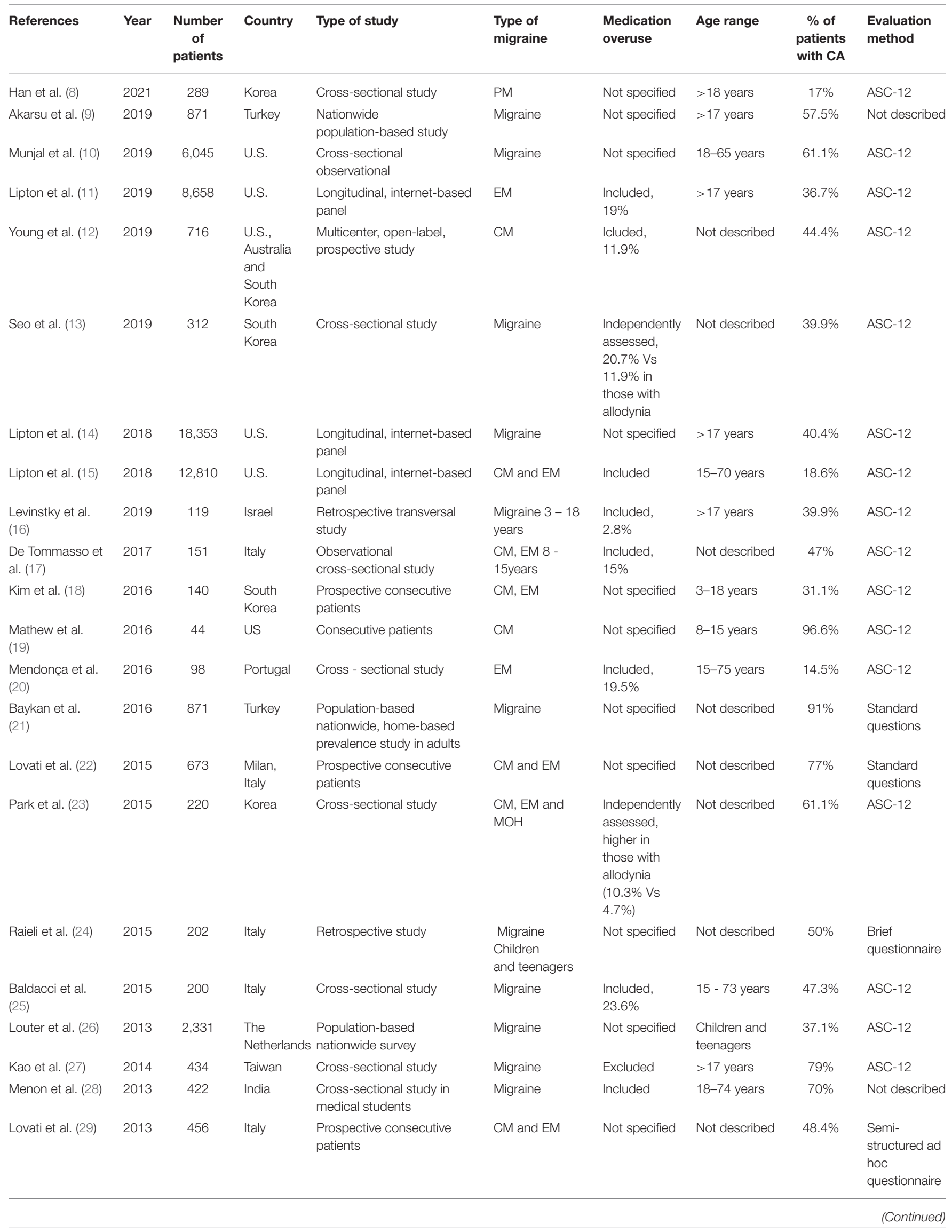


TABLE 1 | Continued

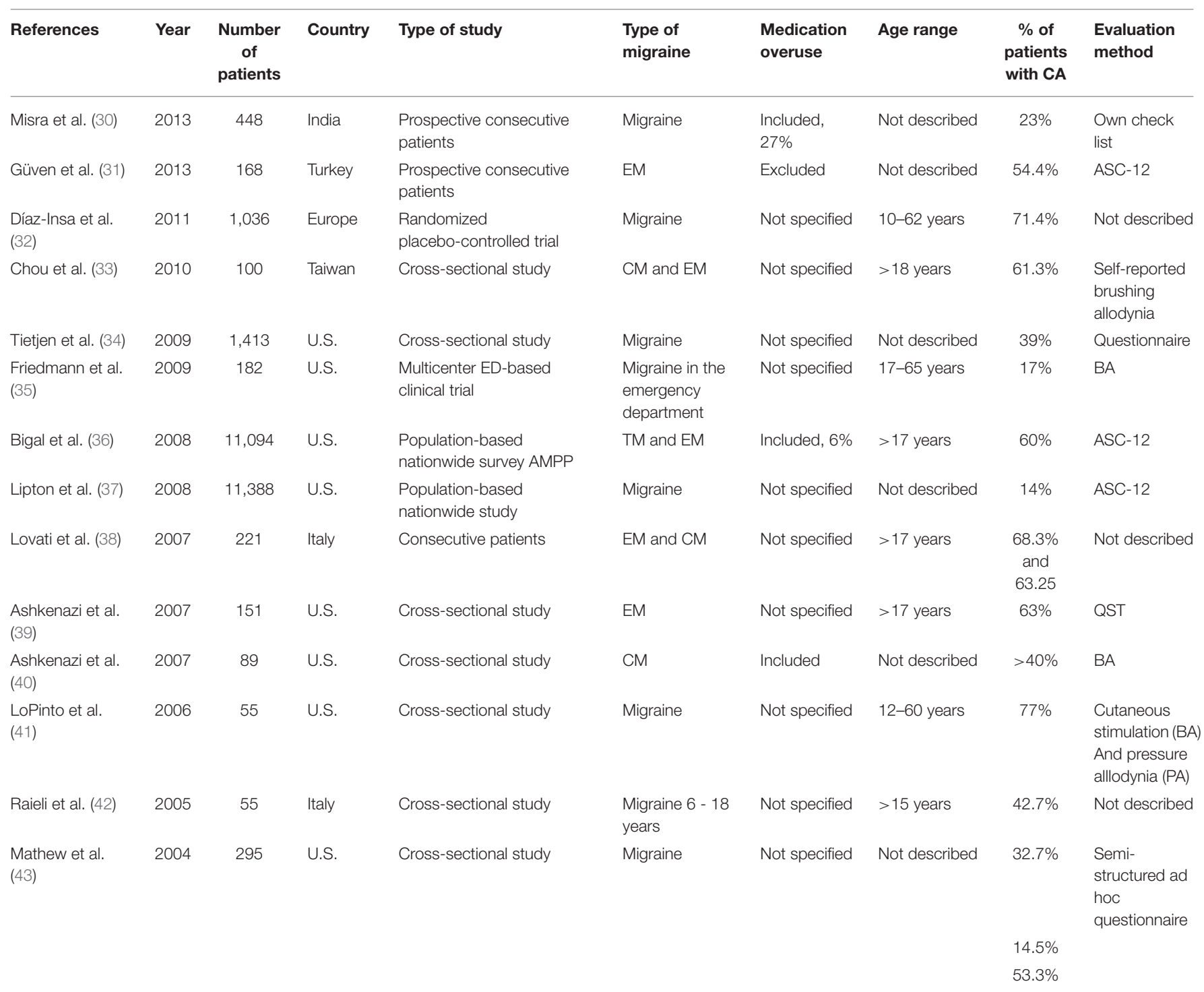

ASC-12, allodynia symptom checklist; BA, brushing allodynia; CM, chronic migraine; EM, episodic migraine; PM, probable migraine (fulfills all but one criterion of migraine); QST, quantitative sensory test; TM, transformed migraine.

nociceptive inputs from the periphery and become sensitized to further stimulus. Central sensitization refers to a condition in which central neurons in the trigeminal nociceptive pathway, mainly TNC second-order neurons or third-order neurons in the thalamus, are sensitized and exhibit increased excitability $(2,43)$. Sensitization of second-order neurons of the TNC explain the appearance of cephalic allodynia in patients with migraine $(47,49)$. It has been observed that once the sensitization of second order trigeminovascular neurons is established, it becomes activity independent, and it maintains itself in the absence of sensory input (54).

Subsequently, nociceptive information ascends from the TNC toward the thalamus. Sensitization of third-order thalamic neurons (especially those located in the pulvinar region) is the mechanism that explains extracephalic allodynia $(2,47,49)$.
Additionally, functional MRI studies also show that the activation pattern of cortical structures after a painful stimulus is different in patients with migraine and allodynia. These findings support the existence of a dysfunction of the trigeminalthalamus-cortical nociceptive pathway, which could specifically affect the cortical areas that modulate thalamocortical inputs $(48,55)$.

Apart from noxious stimuli, sensitization can be activated other mechanisms. Experimentally, it has been observed that CSD is capable of activating peripheral and central trigeminovascular neurons (56). Also, fat excess, may promote chronic release of different inflammatory mediators that decrease the threshold for the onset of a migraine attack and contribute to central sensitization (46). Finally, central sensitization may also be facilitated by the 
impairment of descending inhibitory pain mechanisms on the trigeminovascular system observed in patients with migraine (57).

\section{ASSESSMENT OF ALLODYNIA IN MIGRAINE PATIENTS}

CA is usually classified according to the type of stimulus that causes the sensation of pain. At least three types of CA have been consistently described: thermal allodynia, dynamic mechanical, and static mechanical $(1,7)$. Thermal allodynia is mediated by nociceptive fibers $\mathrm{C}$ and $\mathrm{A} \delta(1,7)$ and is usually assessed with Quantitative Sensory Testing (QST). Dynamic mechanical allodynia is mediated by $A \beta$ mechanoreceptive and $A \beta$ fibers insensitive to capsaicin (7) and is assessed by brushing the skin. Finally, static mechanical allodynia is mediated by $A \delta$ nociceptive fibers (58) and evaluated using von Frey hair filaments.

QST is the gold standard method for assessing allodynia. However, this neurophysiological test requires special equipment, is time-consuming and costly for use in clinical settings. Therefore, initial studies on CA were conducted in very few centers and included highly selected patients $(2,59,60)$. In order to have a method for measuring CA in clinical practice, Lipton et al. developed and validated a questionnaire for assessing CA. The Allodynia Symptom Checklist or ASC-12 (37), was developed by modifying Jakubowski et al. instrument (7) to provide graded allodynia response options, as CA is not an all or none phenomenon. Based on clinical interview, different types of allodynic symptoms could be studied during or immediately after the migraine attacks including cephalic (scalp, face, neck, ears) and extracephalic symptoms (limbs, trunk) (43). The aim was to quantify CA in general based on clinical symptoms and determine if there were natural subtypes of CA (37). ASC-12 has high reliability in detecting patients with CA but low reliability in detecting patients without CA (7). Perhaps the addition of questions aimed at improving this aspect could give the tool even greater value. Nevertheless, this questionnaire helps neurologists identify patients with CA within the time frame of a routine office visit even when the patient is free of migraine (7).

The ASC-12 includes 12 questions on the frequency of various symptoms of CA in association with a headache attack. For people with more than one type of headache, questions are focused on the "most severe type of headache," as it is likely to be migraine (61). The response categories are "never," "rarely," "less than half the time," and "half the time or more." According to previous studies, the option "rarely" is considered a negative answer and the objective of its presence is to reduce false positives $(37,62,63)$. Additionally, subjects can also indicate that an item "does not apply to me" that option is for someone who has never shaved their face or someone who has never worn a ponytail. The ASC-12 items are scored as 0 (that is, never, rarely, or do not apply to me), 1 (less than half the time), and 2 (half the time or more), so the score can range from 0 to 24 and in its validation the following categories are defined based on the total scores obtained, being: non-allodynia $0-2$, mild allodynia 3-5, moderate allodynia 6-8 and severe allodynia $\geq 9$ (37).

\section{USE OF ALLODYNIA AS A READOUT OF MIGRAINE-LIKE PAIN IN PRECLINICAL MODELS}

Preclinical models have greatly enhanced our current understanding of migraine; hence they are considered an invaluable tool for investigating this disorder. One of the most used and easiest to quantify readout in preclinical models of migraine is CA (64), which indicates the importance attributed to CA within the field of migraine research. CA can be measured in preclinical models by using either mechanical or thermal sensory nociceptive thresholds, which have been shown to be reliable markers of migraine pathophysiology (65).

Mechanical allodynia is the most used method for studying pain-like behavior in preclinical models of headache, and it is assessed with the von Frey test. This method uses calibrated von Frey filaments which are applied to the periorbital region (cephalic) or hind paw (extracephalic) of rodents to determine evoked response thresholds (64). Von Frey test is used to assess responses to different substances, such as the dural inflammatory soup and the administration of algogenic substances, nytroglicerin, CGRP, amylin or pituitary adenylate cyclase-activating polypeptide (PACAP), among others $(66,67)$. The translational utility of this test has been crucial to investigate the underlying mechanisms of several migraine treatments and to predict the efficacy of new therapies. Some of the treatments positively tested to date include triptans $(68,69)$, which in turn are also used as a positive control in these tests; gepants (69); CGRP monoclonal antibodies (69); ditans (70); and opioid receptor agonists (71).

Although most preclinical studies are focused on assessing mechanical allodynia, thermal allodynia (cold and hot) can also be easily assessed, and both measures can complement each other to enhance our understanding of the mechanisms involved in migraine pathophysiology. Thermal allodynia can be measured with different methodologies including the Hargreaves' test (73), based on applying a heat stimulus to the hind paws or tail of the animal to measure their withdrawal latency; and the acetone evaporation test, which measures the aversive behaviors elicited by evaporative cooling both in cephalic or extracephalic regions (74). These tests have been used in preclinical models of migraine, where the administration of nitroglycerin and algogenic substances have shown to increase thermal allodynia $(67,68)$, and the nasocilary nerve ligation to increase sensitization to acetone evaporation (75).

Basic science has proven to be a fundamental pillar for the development of knowledge in migraine and in the relevance of $\mathrm{CA}$ in it. Hence the value of continuing to use animal models that resemble the human and thus be able to deepen the knowledge on this area.

\section{ALLODYNIA AND MIGRAINE CHRONIFICATION}

The presence of CA is currently considered as a possible marker and a risk factor for migraine chronification $(19,26)$ (Table 2). 
TABLE 2 | Summary of the studies analyzing the prevalence of CA in Episodic Migraine (EM) vs. Chronic Migraine (CM) (in \%) and those identifying CA as a risk factor for migraine chronification (NA, Not Applicable; TTH, Tension Type Headache; HTTH, Chronic Tension Type Headache).

\begin{tabular}{lcclccc}
\hline References & Year & $\begin{array}{c}\text { Number of } \\
\text { patients }\end{array}$ & Country & $\begin{array}{c}\text { CA as a risk } \\
\text { factor for } \\
\text { chronification }\end{array}$ & $\begin{array}{c}\text { Type of migraine } \\
\text { CA prevalence } \\
\text { in EM \% }\end{array}$ & $\begin{array}{c}\text { CA prevalence } \\
\text { in CM \% }\end{array}$ \\
\hline Russo et al. (55) & 2020 & 50 & ttaly & YES & Migraine & NA \\
Mathew et al. (19) & 2016 & 44 & U.S. & YES & CM & - \\
Louter et al. (26) & 2013 & 3,029 & Netherlands & YES & Migraine & - \\
Tietjen et al. (34) & 2009 & 1,413 & U.S. & NA & Migraine & - \\
\end{tabular}

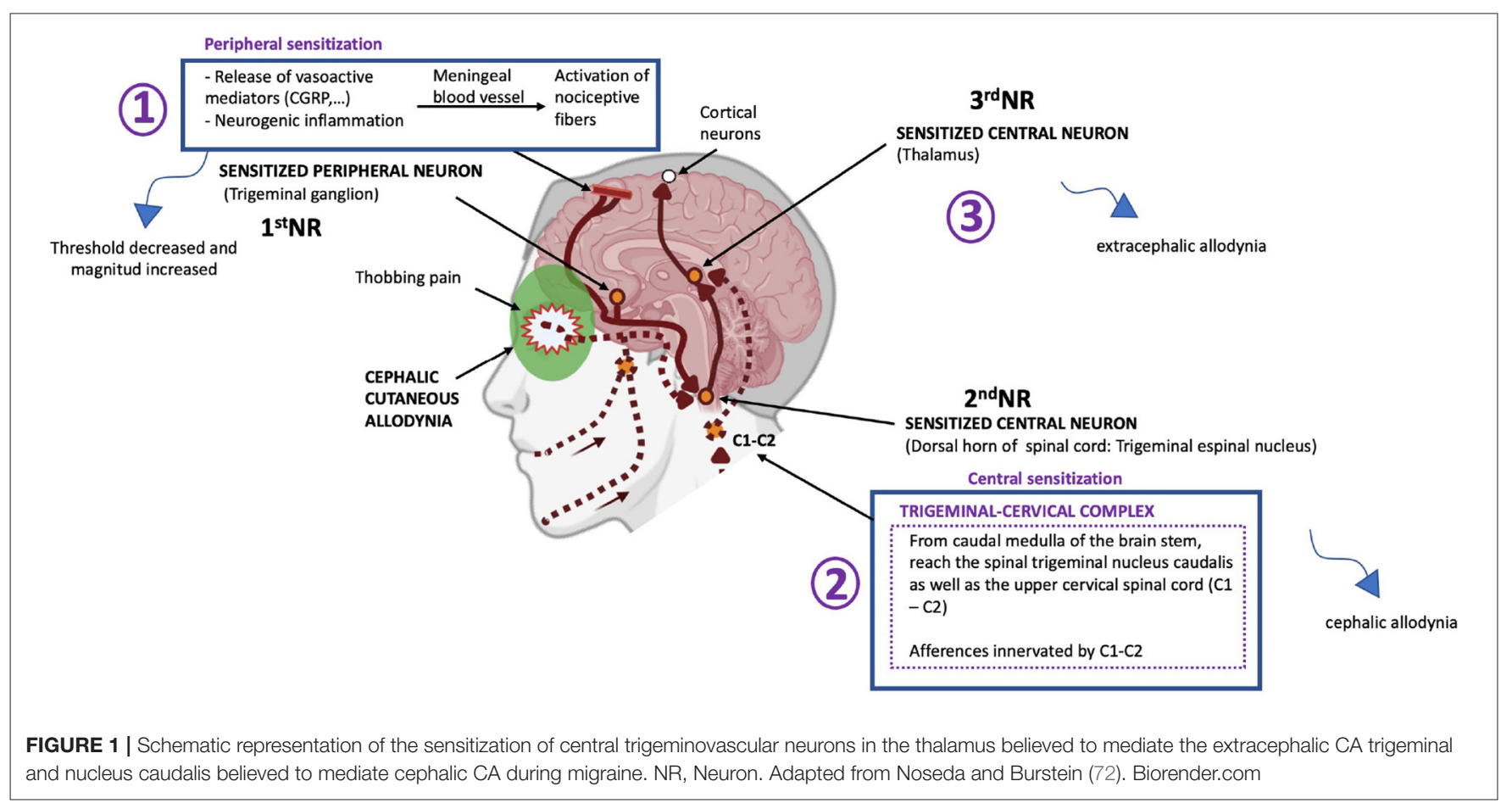

$\mathrm{CA}$ is more common in patients with frequent attacks, and long-lasting disease $(19,26,34,36,37)$. The increased headache frequency, disability, and longer duration of illness indicate that either CA is a marker for a more severe migraine disorder or that repeated attacks over a long period can lead to development of CA $(26,34)$.

The association between CA and migraine frequency may be explained by the repetitive activation of trigemino-talamocortical nociceptive pathway. Recurrent migraine attacks with CA leads to a decreased threshold for subsequent migraine attacks (76) but may also induce functional changes in different structures involved in pain modulation, such as periaqueductal gray $(26,36)$, the spinal trigeminal nucleus and posterior thalamus (77). Rome et al. give another explanation using a nociception-induced plasticity model suggesting that a noxious stimulus may, under certain conditions, lead to a sensitized corticolimbic state, and pain chronification (26).

On the other hand, lower thermal pain thresholds on cutaneous testing have been noted during an attack among patients with migraine and CA (19). When tested with a functional magnetic resonance imaging (MRI) study using blood oxygen-level-dependent (BOLD) contrastsensitive sequences, the patients with migraine with CA showed more prominent periaqueductal gray and nucleus cuneiformis resting state connectivity with other brainstem, thalamic, insula, and cerebellar regions that process pain when compared to patients with migraine with no-CA (19). Resting state connectivity in this population was also found to be stronger, with frontal and temporal regions suggesting differences in higher-order pain modulation (78). These thermal threshold and MRI BOLD imaging data further clarify that the presence of CA is probably a risk factor for the transformation from episodic to chronic migraine (19). A deeper understanding of CA and how it is related to chronification of migraine may elucidate the exact pathophysiological mechanisms and can provide a rationale for adequate treatment of this difficult to manage migraine form (76). 


\section{IMPLICATIONS OF ALLODYNIA FOR MIGRAINE TREATMENT}

The efficacy of the treatment of migraine attacks is reduced in patients with CA (79). Data from the AMPP study observed that CA has been associated with an increased likelihood of an inadequate response to triptans, non-steroidal anti-inflammatory drugs, opioids, and barbiturates in comparison with patients without CA (80). However, randomized controlled trials did not confirm these findings $(81,82)$. The impact of CA on treatment outcomes in the patients with acute migraine treated with almotriptan was analyzed in the "Act when Mild" study. The presence of CA did not alter the efficacy of almotriptan administered for early/mild pain in terms of 2-h pain-free rates or sustained pain-free rates. CA impaired the effectiveness of almotriptan in patients with moderate to severe pain in terms of longer migraine duration. Therefore, the data from this study suggest that pain intensity is the main driver of triptan response, and not the presence of CA (32).

Available data are not finally conclusive regarding the role of CA in triptan response $(81,82)$. A fundamental question may be the distinction between developing CA, in which central sensitization depends on incoming pain signals from peripheral nociceptors, and established $\mathrm{CA}$, where sensitization becomes independent of pain signals coming from the dura mater (83).

The influence of CA on the response to preventive treatment is currently unknown. Some authors suggest that the effectiveness of oral preventatives is reduced in patients with CA (84). In the same line, the COMPEL study demonstrated that the effect of onabotulinumtoxinA on the reduction of headache days was lower in patients with CA (12). However, the effect of onabotulinumtoxinA on other efficacy measures was similar in patients with and without $\mathrm{CA}$, and the improvement of the MIDAS scale was significantly higher in the former (12). Data available to date do not allow us to conclude with certainty whether the efficacy of preventive treatment is reduced in patients with CA. More studies are needed to clarify this hypothesis. It is possible that in the future, treatments may be personalized based on clinical variables that include the presence of CA.

Considering that main site of action of monoclonal antibodies targeting the CGRP pathway is outside the central nervous system, it is reasonable to hypothesize that these treatments may not be effective in patients with migraine and CA. However, recent studies in migraine patients treated with erenumab for migraine prevention, showed that the presence of CA does not appear to negatively impact on erenumab effectiveness, and the treatment could even reduce the symptoms of allodynia $(85,86)$.

\section{LIMITATIONS AND STRENGTHS}

Some limitations need to be acknowledged in the interpretation of our results. First, this is not a systematic review. We limited our scope to selected articles which we believed could be the most representative ones. Secondly, we relied on PubMed and Cochrane only for our search strategy, which has potentially hampered the scope of our narrative review. Among the strengths of our study, we analyzed an important quantity of articles highlighting the most relevant research on CA and migraine.

\section{SUGGESTIONS FOR FUTURE STUDIES ON ALLODYNIA}

Many questions remain to be clarified about CA and migraine. First, it is very relevant to have a deeper knowledge about the pathophysiology of CA to understand why some patients develop CA and others do not. Second, if the longer duration of migraine indicates that $\mathrm{CA}$ is a marker for more severe disease, and patients with CA start to have migraine at younger age (32), it can be speculated that children and adolescents with $\mathrm{CA}$ and migraine are more prone to chronification at a later stage of their lives. However, this has not been proved, yet and more studies on CA and migraine are needed to verify such correlation in the younger population. Third, the detection of $\mathrm{CA}$ can be done easily in clinical practice and therefore the use of ASC-12 should be promoted. Furthermore, the presence of CA may have implications from the diagnostic point of view due to its association with other comorbidities such as depression or medication overuse. It is not known whether treatment of risk factors reduces the risk of CA. On the other hand, it is also important to define the best strategy to effectively treat acute migraine attacks in patients with CA. Finally, if the risk of migraine progression increases in patients with CA, perhaps the use of preventive drugs should be promoted in patients with this symptom.

\section{CONCLUSIONS}

$\mathrm{CA}$ is common in patients with migraine, reflects the presence of central sensitization, and is associated with migraine progression. The mechanisms underlying CA in migraine are not completely clarified but include a sensitization phenomenon at different levels of the trigemino-talamo-cortical nociceptive pathway and dysfunction of brainstem and cortical areas that modulate thalamocortical inputs. The gold standard for the assessment of CA is QST, but the validated ASC-12 questionnaire is preferred in clinical setting and epidemiological research. CA may increase the probability of a deficient response to acute treatments, but the influence of CA on the effectiveness of preventive medication is uncertain. Clinicians should consider that patients with severe or frequent attacks, who overuse analgesics or with depression, are more likely to develop CA. Addressing these risk factors, may reduce the likelihood of having CA and prevent migraine chronification.

Future studies are necessary to better understand the pathophysiology of CA and to determine how to treat patients with migraine and CA and thus prevent disease progression.

\section{AUTHOR CONTRIBUTIONS}

AM-O: literature review, data processing and analyses, results interpretation, language editing, review and drafting of the first manuscript, and results interpretation. SQ, NM, AL-B, VG, and MV-P: literature review, data processing and analyses, and 
results interpretation. RB and SS-L: critical revision of the manuscript. PI: conception and article design, literature review, results interpretation, and critical revision of the manuscript. All authors contributed to the article and approved the submitted version.

\section{REFERENCES}

1. Woolf CJ. Relative effectiveness of $C$ primary afferent fibers of different origins in evoking a prolonged facilitation of the flexor reflex in the rat. $J$ Neurosci. (1986) 6:1433-42. doi: 10.1523/JNEUROSCI.06-05-01433.1986

2. Burstein R, Yarnitsky D, Goor-Aryeh I, Ransil BJ, Bajwa ZH. An association between migraine and cutaneous allodynia. Ann Neurol. (2000) 47:61424. doi: 10.1002/1531-8249(200005)47:5<614::AID-ANA9>3.0.CO;2-N

3. E. L. On Megrim, Sick-Headache. Nijmegen: Arts and Boeve (1873).

4. Aguggia M, Saracco MG, Cavallini M, Bussone G, Cortelli P. Sensitization and pain. Neurol Sci. (2013) 34 (Suppl. 1):S37-40. doi: 10.1007/s10072-013-1382-0

5. Landy S, Rice K, Lobo B. Central sensitisation and cutaneous allodynia in migraine: implications for treatment. CNS Drugs. (2004) 18:33742. doi: 10.2165/00023210-200418060-00001

6. Polk AN, Protti TA, Smitherman TA. Allodynia and disability in migraine: the mediating role of stress. Headache. (2020) 60:2281-90. doi: 10.1111/head.14012

7. Jakubowski M, Silberstein S, Ashkenazi A, Burstein R. Can allodynic migraine patients be identified interictally using a questionnaire? Neurology. (2005) 65:1419-22. doi: 10.1212/01.wnl.0000183358.53939.38

8. Han SM, Kim KM, Cho SJ, Yang KI, Kim D, Yun CH, et al. Prevalence and characteristics of cutaneous allodynia in probable migraine. Sci Rep. (2021) 11:2467. doi: 10.1038/s41598-021-82080-z

9. Akarsu EO, Baykan B, Ertas M, Zarifoglu M, Kocasoy Orhan E, Saip S, et al. Sex differences of migraine: results of a nationwide home-based study in Turkey. Noro Psikiyatr Ars. (2020) 57:126-30. doi: 10.29399/npa.23240

10. Munjal S, Singh P, Reed ML, Fanning K, Schwedt TJ, Dodick DW, et al. Most bothersome symptom in persons with migraine: results from the migraine in America symptoms and treatment (MAST) Study. Headache. (2020) 60:41629. doi: 10.1111/head.13708

11. Lipton RB, Fanning KM, Buse DC, Martin VT, Hohaia LB, Adams $\mathrm{AM}$, et al. Migraine progression in subgroups of migraine based on comorbidities: results of the CaMEO Study. Neurology. (2019) 93:e222436. doi: $10.1212 /$ WNL.0000000000008589

12. Young WB, Ivan Lopez J, Rothrock JF, Orejudos A, Manack Adams A, Lipton $\mathrm{RB}$, et al. Effects of onabotulinumtoxinA treatment in patients with and without allodynia: results of the COMPEL study. J Headache Pain. (2019) 20:10. doi: 10.1186/s10194-018-0952-1

13. Seo JG, Park SP. Clinical significance of sensory hypersensitivities in migraine patients: does allodynia have a priority on it? Neurol Sci. (2019) 40:3938. doi: 10.1007/s10072-018-3661-2

14. Lipton RB, Munjal S, Alam A, Buse DC, Fanning KM, Reed ML, et al. Migraine in America symptoms and treatment (MAST) study: baseline study methods, treatment patterns, and gender differences. Headache. (2018) 58:1408-26. doi: 10.1111/head.13407

15. Lipton RB, Fanning KM, Buse DC, Martin VT, Reed ML, Manack Adams A, et al. Identifying natural subgroups of migraine based on comorbidity and concomitant condition profiles: results of the chronic migraine epidemiology and outcomes (CaMEO) study. Headache. (2018) 58:933-47. doi: 10.1111/head.13342

16. Levinsky Y, Zeharia A, Eidlitz-Markus T. Cephalic cutaneous allodynia in children and adolescents with migraine of short duration: a retrospective cohort study. Cephalalgia. (2019) 39:61-7. doi: 10.1177/0333102418776018

17. de Tommaso M, Sciruicchio V, Delussi M, Vecchio E, Goffredo M, Simeone $\mathrm{M}$, et al. Symptoms of central sensitization and comorbidity for juvenile fibromyalgia in childhood migraine: an observational study in a tertiary headache center. J Headache Pain. (2017) 18:59. doi: 10.1186/s10194-017-0764-8

\section{ACKNOWLEDGMENTS}

We would like to thank to M. F. Olaondo-Preboste and J. D. Mínguez-Carrasco and P. Mínguez-Olaondo for their support and close collaboration.

18. Kim SY, Park SP. Cutaneous allodynia and its risk factors in korean patients with migraine: a survey of two tertiary care hospitals. J Oral Facial Pain Headache. (2016) 30:323-9. doi: 10.11607/ofph.1687

19. Mathew PG, Cutrer FM, Garza I. A touchy subject: an assessment of cutaneous allodynia in a chronic migraine population. J Pain Res. (2016) 9:101-4. doi: 10.2147/JPR.S103238

20. Mendonca MD, Caetano A, Viana-Baptista M, Group CHS. Association of depressive symptoms with allodynia in patients with migraine: a cross-sectional study. Cephalalgia. (2016) 36:1077-81. doi: 10.1177/0333102415620285

21. Baykan B, Ekizoglu E, Karli N, Kocasoy-Orhan E, Zarifoglu M, Saip S, et al. Characterization of migraineurs having allodynia: results of a large population-based study. Clin J Pain. (2016) 32:631-5. doi: 10.1097/AJP.0000000000000301

22. Lovati C, Giani L, Castoldi D, Mariotti D’Alessandro C, DeAngeli F, Capiluppi E, et al. Osmophobia in allodynic migraineurs: cause or consequence of central sensitization? Neurol Sci. (2015) 36 (Suppl. 1):1457. doi: 10.1007/s10072-015-2141-1

23. Park SP, Seo JG, Lee WK. Osmophobia and allodynia are critical factors for suicidality in patients with migraine. J Headache Pain. (2015) 16:529. doi: 10.1186/s10194-015-0529-1

24. Raieli V, Trapolino D, Giordano G, Spitaleri C, Consolo F, Santangelo G, et al. Juvenile migraine and allodynia: results of a retrospective study. Headache. (2015) 55:413-8. doi: 10.1111/head.12530

25. Baldacci F, Lucchesi C, Ulivi M, Cafalli M, Vedovello M, Vergallo A, et al. Clinical features associated with ictal osmophobia in migraine. Neurol Sci. (2015) 36:43-6. doi: 10.1007/s10072-014-1903-5

26. Louter MA, Bosker JE, van Oosterhout WP, van Zwet EW, Zitman FG, Ferrari $\mathrm{MD}$, et al. Cutaneous allodynia as a predictor of migraine chronification. Brain. (2013) 136:3489-96. doi: 10.1093/brain/awt251

27. Kao CH, Wang SJ, Tsai CF, Chen SP, Wang YF, Fuh JL. Psychiatric comorbidities in allodynic migraineurs. Cephalalgia. (2014) 34:211-8. doi: 10.1177/0333102413505238

28. Menon B, Kinnera N. Prevalence and characteristics of migraine in medical students and its impact on their daily activities. Ann Indian Acad Neurol. (2013) 16:221-5. doi: 10.4103/0972-2327.112472

29. Lovati C, Mariotti C, Giani L, D’Amico D, Sinelli A, De Angeli $\mathrm{F}$, et al. Central sensitization in photophobic and non-photophobic migraineurs: possible role of retino nuclear way in the central sensitization process. Neurol Sci. (2013) 34 (Suppl. 1):S133-5. doi: 10.1007/s10072-0131369-x

30. Misra UK, Kalita J, Bhoi SK. Allodynia in migraine: clinical observation and role of prophylactic therapy. Clin J Pain. (2013) 29:577-82. doi: 10.1097/AJP.0b013e31826b130f

31. Guven H, Cilliler AE, Comoglu SS. Cutaneous allodynia in patients with episodic migraine. Neurol Sci. (2013) 34:1397402. doi: 10.1007/s10072-012-1249-9

32. Diaz-Insa S, Goadsby PJ, Zanchin G, Fortea J, Falques M, Vila C. The impact of allodynia on the efficacy of almotriptan when given early in migraine: data from the "Act when mild" study. Int J Neurosci. (2011) 121:65561. doi: 10.3109/00207454.2011.605191

33. Chou CH, Fuh JL, Wu JC, Wang SJ. Comparison of self-reported cutaneous allodynia and brushing allodynia during migraine attacks. Cephalalgia. (2010) 30:682-5. doi: 10.1177/0333102409352910

34. Tietjen GE, Brandes JL, Peterlin BL, Eloff A, Dafer RM, Stein $\mathrm{MR}$, et al. Allodynia in migraine: association with comorbid pain conditions. Headache. (2009) 49:1333-44. doi: 10.1111/j.1526-4610.2009. 01521.x 
35. Friedman B, Bijur P, Greenwald P, Lipton R, Gallagher EJ. Clinical significance of brush allodynia in emergency patients with migraine. Headache. (2009) 49:31-5. doi: 10.1111/j.1526-4610.2008.01266.x

36. Bigal ME, Ashina S, Burstein R, Reed ML, Buse D, Serrano D, et al. Prevalence and characteristics of allodynia in headache sufferers: a population study. Neurology. (2008) 70:1525-33. doi: 10.1212/01.wnl.0000310645.31020.b1

37. Lipton RB, Bigal ME, Ashina S, Burstein R, Silberstein S, Reed ML, et al. Cutaneous allodynia in the migraine population. Ann Neurol. (2008) 63:14858. doi: 10.1002/ana.21211

38. Lovati C, D'Amico D, Rosa S, Suardelli M, Mailland E, Bertora P, et al. Allodynia in different forms of migraine. Neurol Sci. (2007) 28 (Suppl. 2):S220-1. doi: 10.1007/s10072-007-0781-5

39. Ashkenazi A, Silberstein S, Jakubowski M, Burstein R. Improved identification of allodynic migraine patients using a questionnaire. Cephalalgia. (2007) 27:325-9. doi: 10.1111/ j.1468-2982.2007.01291.x

40. Ashkenazi A, Sholtzow M, Shaw JW, Burstein R, Young WB. Identifying cutaneous allodynia in chronic migraine using a practical clinical method. Cephalalgia. (2007) 27:111-7. doi: 10.1111/j.1468-2982.2006.01255.x

41. LoPinto C, Young WB, Ashkenazi A. Comparison of dynamic (brush) and static (pressure) mechanical allodynia in migraine. Cephalalgia. (2006) 26:852-6. doi: 10.1111/j.1468-2982.2006.01121.x

42. Raieli V, Pandolfi E, La Vecchia M, Puma D, Calo A, Celauro A, et al. The prevalence of allodynia, osmophobia and red ear syndrome in the juvenile headache: preliminary data. J Headache Pain. (2005) 6:2713. doi: 10.1007/s10194-005-0205-y

43. Mathew NT, Kailasam J, Seifert T. Clinical recognition of allodynia in migraine. Neurology. (2004) 63:84852. doi: 10.1212/01.WNL.0000137107.27585.F7

44. Dodick DW, Reed ML, Fanning KM, Munjal S, Alam A, Buse DC, et al. Predictors of allodynia in persons with migraine: results from the Migraine in America Symptoms and Treatment (MAST) study. Cephalalgia. (2019) 39:873-82. doi: $10.1177 / 0333102418825346$

45. Lipton RB, Munjal S, Buse DC, Fanning KM, Bennett A, Reed ML. Predicting inadequate response to acute migraine medication: results from the American migraine prevalence and prevention (AMPP) study. Headache. (2016) 56:1635-48. doi: 10.1111/head.12941

46. Minguez-Olaondo A, Martinez-Valbuena I, Romero S, Fruhbeck G, Luquin MR, Martinez-Vila E, et al. Excess abdominal fat is associated with cutaneous allodynia in individuals with migraine: a prospective cohort study. J Headache Pain. (2020) 21:9. doi: 10.1186/s10194-020-1082-0

47. Burstein R, Noseda R, Borsook D. Migraine: multiple processes, complex pathophysiology. J Neurosci. (2015) 35:661929. doi: 10.1523/JNEUROSCI.0373-15.2015

48. Maleki N, Szabo E, Becerra L, Moulton E, Scrivani SJ, Burstein R, et al. Ictal and interictal brain activation in episodic migraine: neural basis for extent of allodynia. PLoS ONE. (2021) 16:e0244320. doi: 10.1371/journal.pone.0244320

49. Dodick DW. A phase-by-phase review of migraine pathophysiology. Headache. (2018) 58 (Suppl. 1):4-16. doi: 10.1111/head. 13300

50. Iyengar S, Ossipov MH, Johnson KW. The role of calcitonin gene-related peptide in peripheral and central pain mechanisms including migraine. Pain. (2017) 158:543-59. doi: 10.1097/j.pain.0000000000000831

51. Irimia P, Martinez-Valbuena I, Minguez-Olaondo A, Dominguez-Vivero C, Sanchez-Arias JA, Martinez-Vila E, et al. Interictal amylin levels in chronic migraine patients: a case-control study. Cephalalgia. (2021) 41:60412. doi: $10.1177 / 0333102420977106$

52. Ghanizada H, Al-Karagholi MA, Walker CS, Arngrim N, Rees T, Petersen J, et al. Amylin analog pramlintide induces migraine-like attacks in patients. Ann Neurol. (2021) 89:1157-71. doi: 10.1002/ana.26072

53. Goadsby PJ, Holland PR, Martins-Oliveira M, Hoffmann J, Schankin C, Akerman S. Pathophysiology of migraine: a disorder of sensory processing. Physiol Rev. (2017) 97:553-622. doi: 10.1152/physrev.000 34.2015

54. Bernstein C, Burstein R. Sensitization of the trigeminovascular pathway: perspective and implications to migraine pathophysiology. J Clin Neurol. (2012) 8:89-99. doi: 10.3988/jcn.2012.8.2.89
55. Russo A, Esposito F, Conte F, Fratello M, Caiazzo G, Marcuccio $\mathrm{L}$, et al. Functional interictal changes of pain processing in migraine with ictal cutaneous allodynia. Cephalalgia. (2017) 37:305-14. doi: 10.1177/0333102416644969

56. Zhang X, Levy D, Kainz V, Noseda R, Jakubowski M, Burstein R. Activation of central trigeminovascular neurons by cortical spreading depression. Ann Neurol. (2011) 69:855-65. doi: 10.1002/ana.22329

57. Iyengar S, Johnson KW, Ossipov MH, Aurora SK. CGRP and the trigeminal system in migraine. Headache. (2019) 59:659-81. doi: 10.1111/head. 13529

58. Pitcher GM, Henry JL. Cellular mechanisms of hyperalgesia and spontaneous pain in a spinalized rat model of peripheral neuropathy: changes in myelinated afferent inputs implicated. Eur J Neurosci. (2000) 12:200620. doi: $10.1046 / j .1460-9568.2000 .00087 . x$

59. Bahra A, Matharu MS, Buchel C, Frackowiak RS, Goadsby PJ. Brainstem activation specific to migraine headache. Lancet. (2001) 357:1016-7. doi: 10.1016/S0140-6736(00)04250-1

60. Young WB, Richardson ES, Shukla P. Brush allodynia in hospitalized headache patients. Headache. (2005) 45:9991003. doi: 10.1111/j.1526-4610.2005.05180.x

61. Lipton RB, Stewart WF, Simon D. Medical consultation for migraine: results from the American Migraine Study. Headache. (1998) 38:8796. doi: $10.1046 / j .1526-4610.1998 .3802087 . x$

62. Lipton RB, Stewart WF, Diamond S, Diamond ML, Reed M. Prevalence and burden of migraine in the United States: data from the American Migraine Study II. Headache. (2001) 41:646-57. doi: 10.1046/j.1526-4610.2001.041007646.x

63. Bigal ME, Rapoport AM, Sheftell FD, Tepper SJ, Lipton RB. Chronic migraine is an earlier stage of transformed migraine in adults. Neurology. (2005) 65:1556-61. doi: 10.1212/01.wnl.0000184477.11569.17

64. Harriott AM, Strother LC, Vila-Pueyo M, Holland PR. Animal models of migraine and experimental techniques used to examine trigeminal sensory processing. J Headache Pain. (2019) 20:91. doi: 10.1186/s10194-0191043-7

65. Vuralli D, Wattiez AS, Russo AF, Bolay H. Behavioral and cognitive animal models in headache research. J Headache Pain. (2019) 20:11. doi: 10.1186/s10194-019-0963-6

66. De Logu F, Landini L, Janal MN, Li Puma S, De Cesaris F, Geppetti $\mathrm{P}$, et al. Migraine-provoking substances evoke periorbital allodynia in mice. J Headache Pain. (2019) 20:18. doi: 10.1186/s10194-0190968-1

67. Pradhan AA, Smith ML, McGuire B, Tarash I, Evans CJ, Charles A. Characterization of a novel model of chronic migraine. Pain. (2014) 155:26974. doi: 10.1016/j.pain.2013.10.004

68. Bates EA, Nikai T, Brennan KC, Fu YH, Charles AC, Basbaum $\mathrm{AI}$, et al. Sumatriptan alleviates nitroglycerin-induced mechanical and thermal allodynia in mice. Cephalalgia. (2010) 30:1708. doi: 10.1111/j.1468-2982.2009.01864.x

69. Christensen SL, Petersen S, Kristensen DM, Olesen J, Munro G. Targeting CGRP via receptor antagonism and antibody neutralisation in two distinct rodent models of migraine-like pain. Cephalalgia. (2019) 39:182737. doi: $10.1177 / 0333102419861726$

70. Saengjaroentham C, Strother LC, Dripps I, Sultan Jabir MR, Pradhan A, Goadsby PJ, et al. Differential medication overuse risk of novel anti-migraine therapeutics. Brain. (2020) 143:2681-8. doi: 10.1093/brain/ awaa211

71. Bertels Z, Witkowski WD, Asif S, Siegersma K, van Rijn RM, Pradhan AA. A non-convulsant delta-opioid receptor agonist, KNT-127, reduces cortical spreading depression and nitroglycerin-induced allodynia. Headache. (2021) 61:170-8. doi: 10.1111/head.14019

72. Noseda R, Burstein R. Migraine pathophysiology: anatomy of the trigeminovascular pathway and associated neurological symptoms, cortical spreading depression, sensitization, and modulation of pain. Pain. (2013) 154 (Suppl. 1):S44-53. doi: 10.1016/j.pain.2013.07.021

73. Hargreaves K, Dubner R, Brown F, Flores C, Joris J. A new and sensitive method for measuring thermal nociception in cutaneous hyperalgesia. Pain. (1988) 32:77-88. doi: 10.1016/0304-3959(88)90026-7 
74. Yoon C, Wook YY, Sik NH, Ho KS, Mo CJ. Behavioral signs of ongoing pain and cold allodynia in a rat model of neuropathic pain. Pain. (1994) 59:369-76. doi: 10.1016/0304-3959(94)90023-X

75. Akcali D, Belen AD, Babacan A, Bolay H. Nitroglycerin challenge induces lateralized headache in nasociliarynerve-ligated rats: implications for chronic migraine. Turk J Med Sci. (2017) 47:681-8. doi: 10.3906/sag1602-86

76. Weissman-Fogel I, Sprecher E, Granovsky Y, Yarnitsky D. Repeated noxious stimulation of the skin enhances cutaneous pain perception of migraine patients in-between attacks: clinical evidence for continuous sub-threshold increase in membrane excitability of central trigeminovascular neurons. Pain. (2003) 104:693-700. doi: 10.1016/S0304-3959(03)00159-3

77. Kagan R, Kainz V, Burstein R, Noseda R. Hypothalamic and basal ganglia projections to the posterior thalamus: possible role in modulation of migraine headache and photophobia. Neuroscience. (2013) 248:35968. doi: 10.1016/j.neuroscience.2013.06.014

78. Schwedt TJ, Krauss MJ, Frey K, Gereau RW. Episodic and chronic migraineurs are hypersensitive to thermal stimuli between migraine attacks. Cephalalgia. (2011) 31:6-12. doi: 10.1177/0333102410365108

79. Burstein R, Collins B, Jakubowski M. Defeating migraine pain with triptans: a race against the development of cutaneous allodynia. Ann Neurol. (2004) 55:19-26. doi: 10.1002/ana.10786

80. Bigal ME, Buse DC, Chen YT, Golden W, Serrano D, Chu MK, et al. Rates and predictors of starting a triptan: results from the American Migraine Prevalence and Prevention Study. Headache. (2010) 50:14408. doi: 10.1111/j.1526-4610.2010.01703.x

81. Tfelt-Hansen P. Maximum effect of triptans in migraine? A comment. Cephalalgia. (2008) 28:767-8. doi: 10.1111/ j.1468-2982.2007.01415.x

82. Goadsby PJ, Zanchin G, Geraud GA, De Klippel N, Diaz-Insa S, Gobel H, et al. Early vs. nonearly intervention in acute migraine- Act when Mild (AwM). A double-blind, placebo-controlled trial of almotriptan. Cephalalgia. (2008) 28:383-91. doi: 10.1111/j.1468-2982.2008.01546.x
83. Schürks M DH. Migraine, allodynia, and implications for treatment. Eur J Neurol. (2008) 5:1279-85. doi: 10.1111/j.1468-1331.2008.02343.x

84. Delussi M, Vecchio E, Libro G, Quitadamo S, de Tommaso M. Failure of preventive treatments in migraine: an observational retrospective study in a tertiary headache center. BMC Neurol. (2020) 20:256. doi: 10.1186/s12883-020-01839-5

85. Ornello R, Casalena A, Frattale I, Gabriele A, Affaitati G, Giamberardino $\mathrm{MA}$, et al. Real-life data on the efficacy and safety of erenumab in the Abruzzo region, central Italy. J Headache Pain. (2020) 21:32. doi: 10.1186/s10194-020-01102-9

86. Lipton RB, Burstein R, Buse DC, Dodick DW, Koukakis R, Klatt J, et al. Efficacy of erenumab in chronic migraine patients with and without ictal allodynia. Cephalalgia. (2021) 41:1152-60. doi: 10.1177/03331024211010305

Conflict of Interest: The authors declare that the research was conducted in the absence of any commercial or financial relationships that could be construed as a potential conflict of interest.

Publisher's Note: All claims expressed in this article are solely those of the authors and do not necessarily represent those of their affiliated organizations, or those of the publisher, the editors and the reviewers. Any product that may be evaluated in this article, or claim that may be made by its manufacturer, is not guaranteed or endorsed by the publisher.

Copyright (C) 2022 Mínguez-Olaondo, Quintas, Morollón Sánchez-Mateos, LópezBravo, Vila-Pueyo, Grozeva, Belvís, Santos-Lasaosa and Irimia. This is an openaccess article distributed under the terms of the Creative Commons Attribution License (CC BY). The use, distribution or reproduction in other forums is permitted, provided the original author(s) and the copyright owner(s) are credited and that the original publication in this journal is cited, in accordance with accepted academic practice. No use, distribution or reproduction is permitted which does not comply with these terms. 